Research Article

\title{
Simulation of the Compressive Strength of Cemented Tailing Backfill through the Use of Firefly Algorithm and Random Forest Model
}

\author{
Qi-Ang Wang, ${ }^{1}$ Jia Zhang, ${ }^{2}$ and Jiandong Huang $\mathbb{D}^{2}$ \\ ${ }^{1}$ State Key Laboratory for Geomechanics and Deep Underground Engineering and School of Mechanics and Civil Engineering, \\ China University of Mining and Technology, Xuzhou 221116, China \\ ${ }^{2}$ School of Mines, China University of Mining and Technology, Xuzhou 221116, China
}

Correspondence should be addressed to Jiandong Huang; huang@cumt.edu.cn

Received 2 February 2021; Accepted 25 June 2021; Published 8 July 2021

Academic Editor: Letícia Fleck Fadel Miguel

Copyright (C) 2021 Qi-Ang Wang et al. This is an open access article distributed under the Creative Commons Attribution License, which permits unrestricted use, distribution, and reproduction in any medium, provided the original work is properly cited.

Cemented tailings backfill is widely used in worldwide mining areas, and its development trend is increasing due to the technical and economic benefits. However, there is no reliable and simple machine learning model for the prediction of the compressive strength. In the present study, the research process to use artificial intelligence algorithms to predict the compressive strength of cemented tailing backfill was conducted, overcoming the shortcomings of traditional empirical formulas. Experimental tests to measure the compressive strength of cemented tailing backfill were conducted to construct the dataset for the machine learning. Five input parameters (tailing to cement ratio, percentage of fine tailings, cement type, curing time, and solid to water ratio) were considered for the design of the laboratory tests. The firefly algorithm (FA) was used to tune the random forest (RF) hyperparameters, and it was adopted to combine the RF model to improve the accuracy and efficiency for the prediction of the compressive strength of the cemented tailing backfill. By comparing the predicted and actual results, the reliability and accuracy of the prediction model proposed are confirmed. Tailing to cement ratio and curing time are the two most important parameters to the compressive strength of the cemented tailing backfill.

\section{Introduction}

Grouting, filling, and sealing are the commonly used method for the treatment of underground goaves and leftover gobs [1]. The selection of backfilling materials is one of the key factors that directly affect the quality of the project $[2,3]$. It is a solid material composed of cementitious materials such as soil, sand, stone, block stone, industrial waste residue, and cement used to fill the mined area. Filling materials should be provided with a wide range of sources, low price, easy preparation, and transportation, and the formed filling body should have the required physical and mechanical properties and chemical properties. Among these filling materials, the cemented tailing backfill plays an important role [4-6]. The cement tailings backfill has been widely used in the underground mines in China, and its development trend is increasing due to the many technical and economic benefits it provides. It is typically mixed by the cement, tailings, and water in a factory located on the ground. Afterward, the cemented tailing is transported to the underground mine. With the gradual increase in the mining depth, the stress of the stope also increases. The mechanical properties and longterm service strength of cemented tailing backfill under high-stress conditions are closely related to the safety of the stope. Considering the importance to support stability in the mining area, the cemented tailing backfill has received more and more attention in recent years, especially in the research fields of strength and durability $[2,6]$.

As one of the most important parameters to evaluate the performance of the cemented tailing backfill in the underground mine, the compressive strength has been evaluated in various studies through laboratory tests and the 
corresponding mechanism has been revealed. To obtain enough support for the stability of the mining area, the strength detection of cemented tailing backfill is necessary. Typically, the mine engineers found the optimized mixdesign in the cemented tailing backfill by evaluating the compressive strength of the cemented tailing backfill in the laboratory [7, 8]. However, it should be noted that the experimental research is time-consuming and expensive. Besides, the cemented tailing backfill test is not suitable for a large number of experiments. Some researchers use empirical formulas to predict the compressive strength of cemented tailing backfill, some of which can be used for the prediction, but most of the predicting models are limited by their input as well as dataset $[9,10]$. Due to the low accuracy of the empirical formula, the application of these models is limited $[9,11,12]$. To accurately predict the compressive strength of cemented tailing backfill, simpler and more reliable models should be proposed and used.

To solve this problem, more sophisticated technologies, such as artificial intelligence techniques, should be used to develop more accurate and reliable models. Artificial intelligence models are widely used in the computer-aided design of asphaltic or cementitious materials [13-15]. Unlike the traditional model that uses empirical formulas to extract patterns, the artificial intelligence model can find correlations between mix-design and the compressive strength of the cemented tailing backfill, using the algorithms with the function of pattern recognition to predict the dynamic modulus of asphalt mixtures. Besides, compared with the mathematical models, artificial intelligence models can be easily and effectively extended to big data without requiring a large number of computing resources [15]. The recent research showed that the mechanical properties (such as strength and stiffness) of engineering materials can be accurately predicted by using artificial intelligence technology, reducing the cost of expensive and cumbersome laboratory tests [16-18]. Moreover, the prediction of engineering materials by artificial intelligence can replace the traditional mathematical model and improve the calculation rate and accuracy [19-29].

Among those artificial intelligence models to predict the compressive strength of the cemented tailing backfill, the priority of the random forest (RF) is higher than that of others. RF is composed of multiple decision trees, and there is no correlation between each decision tree in the forest, and the final output of the model is jointly determined by each decision tree in the forest. When dealing with the classification problem, for the test samples, each decision tree in the forest will give the final category. Finally, the output category of each decision tree in the forest will be considered comprehensively to decide the category of the test samples by voting. When dealing with the regression problem, the mean output of each decision tree is taken as the final result. Compared with other algorithms, it has more obvious advantages. Firstly, the accuracy of the prediction is higher. Also, it does not need to consume specific relationships and can use the "permutation importance" technique to measure the importance of input variables [30]. Besides, the application of the RF model is easy to be performed since only two hyperparameters are required to be tuned during the calculation process $[27,31]$.

\section{Research Objective and Overview}

The main purpose of this research is to use artificial intelligence algorithms to predict the compressive strength of cemented tailing backfill to overcome the shortcomings of traditional empirical formulas. Experimental tests to measure the compressive strength of cemented tailing backfill were conducted to construct the dataset for the machine learning. Five input parameters (tailing to cement ratio, percentage of fine tailings, cement type, curing time, and solid to water ratio) were considered for the design of the laboratory tests. The firefly algorithm (FA) was used to tune the RF hyperparameters, and it was adopted to combine the RF model to improve the accuracy and efficiency for the prediction of the compressive strength of the cemented tailing backfill. The results of the training and testing dataset were compared regarding the measured and actual compressive strength, respectively.

\section{Materials and Experimental Tests}

\subsection{Materials}

3.1.1. Cement. Two types of Portland cement P.O32.5R were used in this study. They were supplied by the local manufacturers (Shangfeng cement and Ma'an cement). The basic properties of the two types of cement were evaluated in the laboratory, and the results are given in Table 1.

3.1.2. Tailings. The coarse tailings and fine tailings from the nearby mining area were used in the present study. The gradations of the coarse and fine tailings were measured in the laboratory. Figure 1 gives the results.

3.2. Mix-Design of the Cemented Tailing Backfill. Four parameters were considered in the present study for the mixdesign of the cemented tailing backfill: the ratio of coarse tailings to cement; the fine tailings percentage; the ratio of solid to water; and curing time. Based on the earlier studies, the ratio of the coarse tailings to cement was determined as 4 , 6,8 , and 10 , respectively. Considering the negative influence of the percentage of fine tailings on the compressive strength of the cemented tailing backfill, the fine tailings percentage was determined as $0,0.1,0.15$, and 0.2 , respectively. Taking into account the fluidity of the cemented tailing backfill, the ratio of the solid to water should be lower than 0.72 . Therefore, three ratios $(0.68,0.7$, and 0.72$)$ were determined in this study. The curing time is also an important influencing factor that affects the compressive strength of cement materials. Therefore, the curing time was selected as 7 days, 28 days, and 60 days for the cemented tailing backfill in this study. 
TABLE 1: Testing results of two types of cement.

\begin{tabular}{lccccc}
\hline Cement & $\begin{array}{c}\text { Fineness } \\
(<0.0045 \mathrm{~mm})(\%)\end{array}$ & $\begin{array}{c}\text { Initial solidification } \\
(\mathrm{min})\end{array}$ & $\begin{array}{c}\text { Final solidification } \\
(\mathrm{min})\end{array}$ & $\begin{array}{c}\text { Compressive strength }(28 \\
\text { days })(\mathrm{MPa})\end{array}$ & $\begin{array}{c}\text { Flexural strength }(28 \\
\text { days })(\mathrm{MPa})\end{array}$ \\
\hline Shangfeng & 23.2 & 240 & 305 & 30.7 & 6.5 \\
cement & 6 & 180 & 255 & 39.8 & 8 \\
Ma'an cement & & & & 3 \\
\hline
\end{tabular}

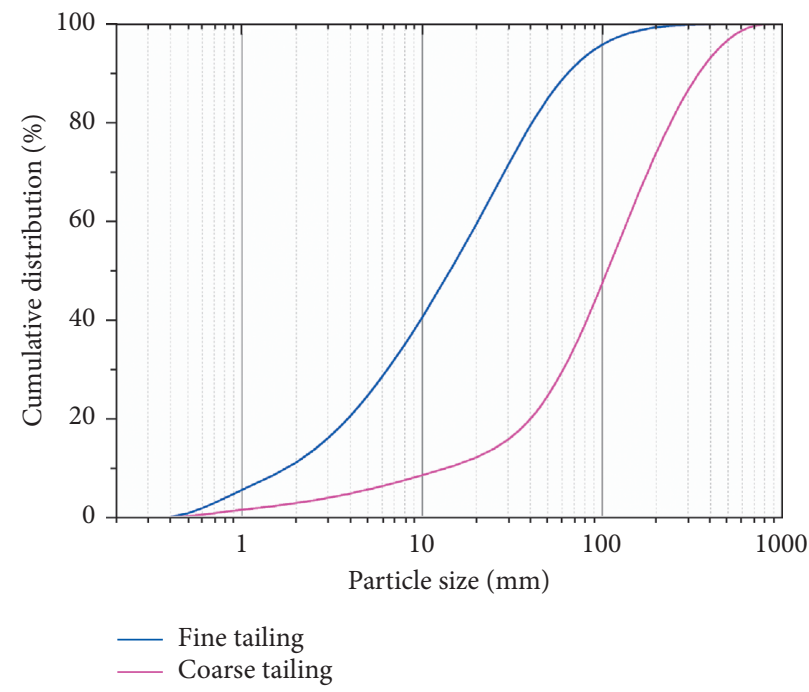

FIgURE 1: Gradations of the coarse and fine tailings.

3.3. Sample Preparations. A laboratory-scale mixer (model: UJZ-15) was used to prepare the samples of the cemented tailing backfill, mixing those raw materials including the cement, coarse tailings, fine tailings, and the water. During this preparation process, the coarse and fine tailings, as well as the cement, were mixed for about 30 seconds firstly. Afterward, the water of the designed content was poured into the mixture. The mixture of the cement, coarse tailings, fine tailings, and the water was mixed for at least 300 seconds until all the materials in the mixer were evenly distributed. Then, the mixture was poured into a cube mold with the size of $70.1 \mathrm{~mm}$ and compacted evenly. After 2 days, the sample of the cemented tailings backfill was demolded and then the specimens were placed under desired temperature $\left(20^{\circ} \mathrm{C}\right)$ and humidity (90\%) for curing.

3.4. Experimental Testing. The experimental tests were conducted per the specification of the China standard GBT50107-2019. In this study, a total of 864 specimens (288 mixtures and 3 repetitions for each mixture) were prepared for the compressive strength using a hydraulic servo testing machine. It should be noted that the compressive strength is typically measured regarding the ASTM standard, where the cylindrical specimens are recommended to be prepared. However, considering the cubic specimens are easier to cast and demold, the cubic samples were prepared in this study. The compressive strength of the cylindrical specimen can be conversed from a cubic specimen by the following equation:

$$
f_{\text {cylider }}=1.05 f_{\text {cube }}\left[0.76+0.2 \times \log \left(\frac{6.89 \times 10^{-3} f_{\text {cube }}}{2840}\right)\right] \text {, }
$$

where $f_{\text {cylinder }}$ represents the compressive strength of cylindrical sample with the diameter of $150 \mathrm{~mm}$ and height of $300 \mathrm{~mm}$, in $\mathrm{MPa}$, and $f_{\text {cube }}$ represents the compressive strength of the cubical sample with the size of $70.1 \mathrm{~mm}$, in $\mathrm{MPa}$. The single axis compressive strength was employed in the present study.

\section{Research Methodology}

4.1. Single Regression Tree (RT). Regarding the regression tree (RT), a set of regions is divided from the feature space. For these regions, each one fits into a simple model. If it is assumed that $X$ and $Y$ are the two prediction variables from the regression problem, two regions are firstly divided from the feature space and response variables are modeled in each region.

Then, each region is deeper divided, and the output parameter is modeled in each of the four newly obtained regions. When the stop criterion is met, the process will stop. The feature space has been divided into four regions. In each division, by selecting the division points and output parameters, the optimized fit can be obtained. The size of the tree is defined as the number of end nodes (e.g., 4 in the present example). 
To predict the dynamic modulus of the asphalt mixtures, it is assumed that the regression problem is represented by

$$
\left\{\begin{array}{l}
\left(y_{i}, x_{i 1}, x_{i 2}, \ldots x_{i j}, \ldots, x_{i p}\right) \text { for } i=1,2, \ldots, n \\
j=1,2, \ldots, p
\end{array}\right.
$$

where $n$ represents the number of the dataset; $p$ represents the number of the attributes; $y$ represents a particular combination of influence variables $\left(x_{i 1}, x_{i 2}, \ldots x_{i j}, \ldots, x_{i p}\right)$; and $x_{i j}$ represents the attribute. The dataset should be divided into $m$ classes $\left(A_{1}, A_{2}, \ldots, A_{m}\right)$ to fit the model of RT. Finally, the sum of squares of these all classes is minimized to obtain the optimized segmentation. This single RT is a basic way to form the structure of the RF model [27]. The detailed introduction for the RF will be presented in the following subchapter.

4.2. Random Forest $(R F)$. During the RF training, lots of decorrelation RTs were produced. Each RT grows in the random segmentation subset of the training dataset $S_{n}$. Afterward, the RF combined all the RT by the so-called bagging method [32]. In this way, the prediction accuracy can be improved by reducing the variance associated with the prediction [32].

The specific execution steps of RF are as follows. (1) A certain number of samples are randomly selected from the training set as the root node samples of each tree; (2) During the establishment of the decision tree, a certain number of candidate attributes were randomly selected and the most appropriate attributes were selected as splitting nodes; (3) After the random forest is established, each decision tree for type output or regression output for test samples is entered; the mean value of the output of each decision tree is used as the final result.

In this process, $n$ samples are randomly selected from the training dataset $S_{n}$ and the selecting probability for each sample is $1 / n$. The $n$ samples randomly collected were named as bootstrap sample $S_{n}^{\Theta}$, where $\Theta$ represents an independently distributed vector. It is assumed that $q$ bootstrap samples $\left(S_{n}^{\Theta_{1}}, S_{n}^{\Theta_{2}}, \ldots, S_{n}^{\Theta_{q}}\right)$ are determined employing the bagging algorithm, and $q$ RTs are trained on the following subdataset:

$$
\widehat{h}\left(X, S_{n}^{\Theta_{1}}\right), \widehat{h}\left(X, S_{n}^{\Theta_{2}}\right), \ldots, \widehat{h}\left(X, S_{n}^{\Theta_{q}}\right) .
$$

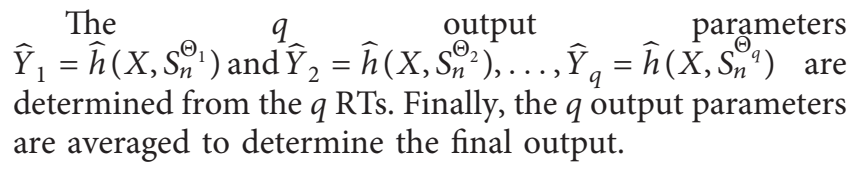

4.3. Firefly Algorithm (FA). The FA is a kind of imitating the information exchange between fireflies, attracting each other to gather and guarding against danger. Figure 2 gives the flowchart of the FA.

In the firefly algorithm, the position of each firefly is a feasible solution to the problem to be solved, and the brightness of the firefly is the fitness of the firefly's position. The higher the brightness, the better the position of the

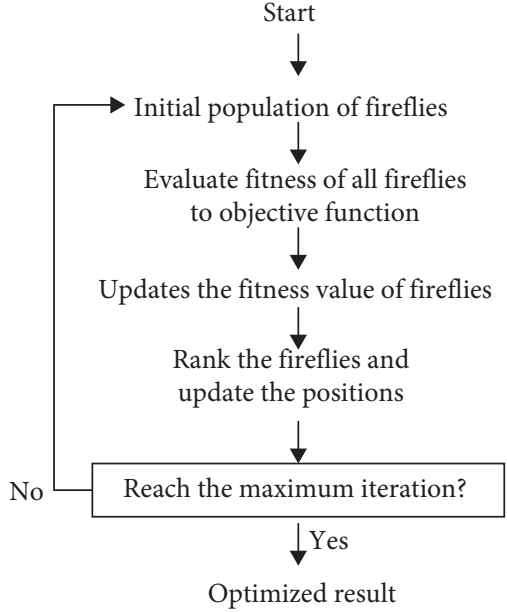

FIGURE 2: Flowchart of the firefly algorithm (FA).

individual firefly in the solution space. Among individual fireflies, high-luminance fireflies attract low-luminance fireflies. In the solution space, each firefly will fly like a firefly with a higher brightness than its own to search for a better position. The greater the brightness, the greater the attraction to other fireflies. At the same time, the light transmission medium between fireflies will absorb light, reduce the brightness of light, and affect the transmission of light. Therefore, the attraction between fireflies will be inversely proportional to the spatial distance; that is, the attraction between two fireflies will decrease as the distance between the two fireflies increases.

\subsection{Evaluating and Calibrating Methods}

4.4.1. Methods to Evaluate the Performance. The prediction performance of the proposed method was calibrated by the parameter, root mean square error (RMSE) [33], which calculates the difference between the predicted and actual measured values using the following equation:

$$
\mathrm{RMSE}=\sqrt{\frac{1}{n} \sum_{i=1}^{n}\left(y_{i}^{*}-y_{i}\right)^{2}}
$$

where $y_{i}^{*}$ and $y_{i}$ present the predicted value and actual measured value, respectively, and $n$ presents the number of data samples. Another parameter for the evaluation of the predicting performance is the correlation coefficient $(R)$, which is determined by the correlation between the predicted and actual values. It can be given by the following equation [34]:

$$
R=\frac{\sum_{i=1}^{n}\left(y_{i}^{*}-\overline{y^{*}}\right)\left(y_{i}-\bar{y}\right)}{\sqrt{\sum_{i=1}^{n}\left(y_{i}^{*}-\overline{y^{*}}\right)^{2}} \sqrt{\sum_{i=1}^{n}\left(y_{i}-\bar{y}\right)^{2}}},
$$

where $\overline{y^{*}}$ is the mean value for the predicted ones and $\bar{y}$ is the mean value for the actual ones. 


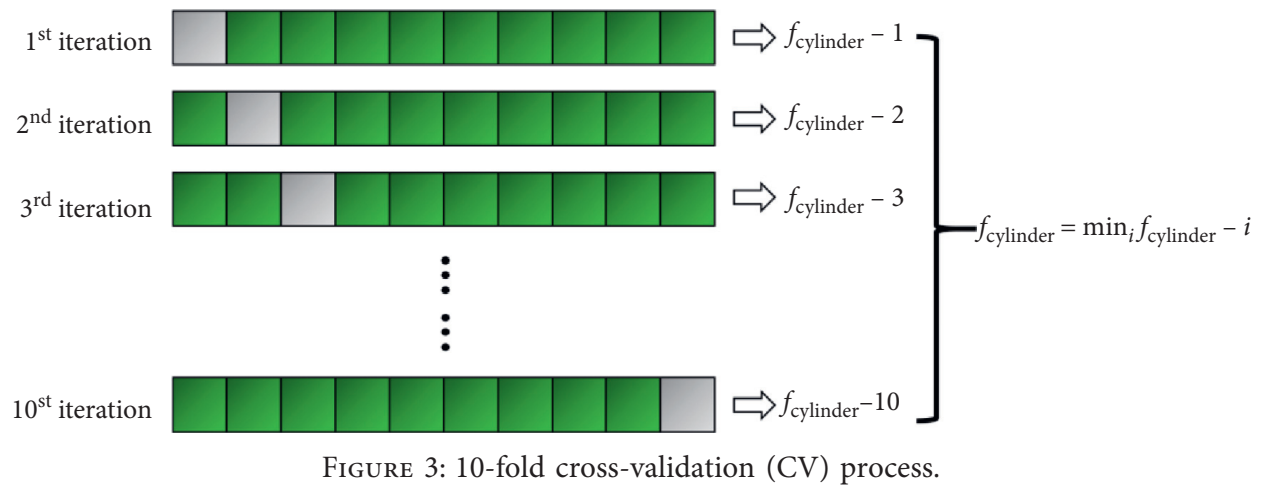

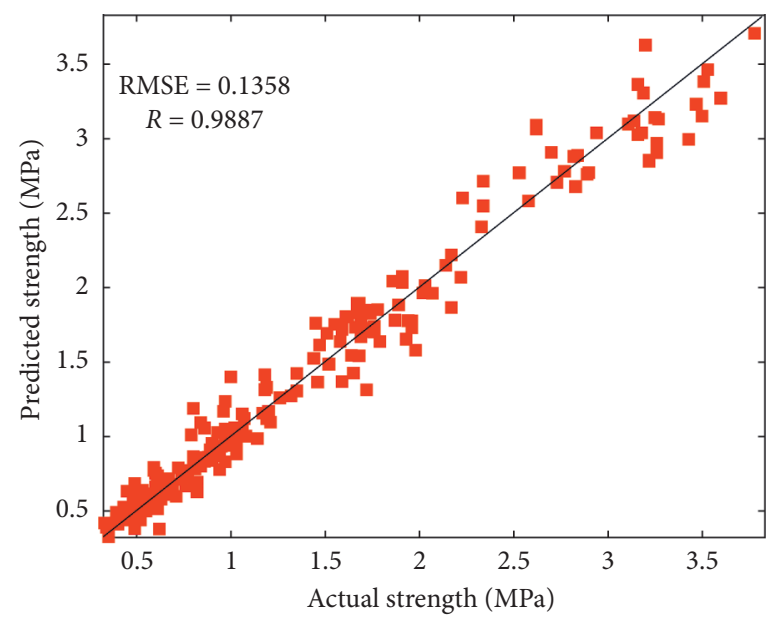

(a)

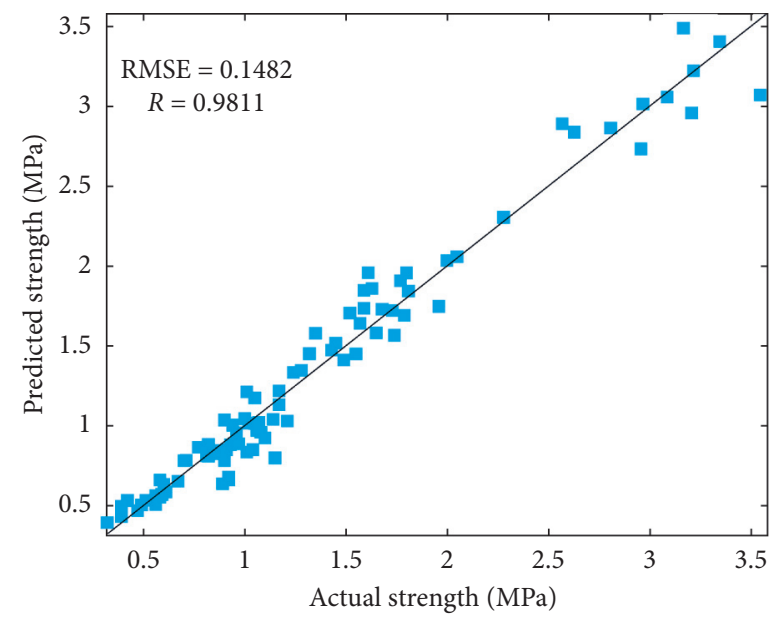

(b)

FIgURE 4: Actual measured vs. predicted values of the compressive strength of the cemented tailing backfill: (a) training dataset; (b) testing dataset.

4.4.2. K-Fold Cross-Validation. Regarding the calibration of the regression model, the simple substitution method, bolstered method, holdout method, and bootstrap method have been applied in the earlier studies [35-37]. Among these methods used to validate the training data, one of the most widely used $k$-fold cross-validation (CV) [38] was used in this study. Specifically, $k$ was given as 10 considering the recommendation from the earlier study [39]. Therefore, the dataset for the training was split into 10 folds during the process of hyperparameter tuning. The algorithms were trained by 9 folds and validated by 1 fold regarding the 10 folds. This procedure should be repeated 10 times, using a different fold as validation for each repetition. The final result was determined as the one with the least error at one fold. The abovementioned CV process is summarized in Figure 3.

\section{Results and Analysis}

5.1. Model Evaluation. Figure 4 presents the comparisons of the predicted and actual compressive strength of the cemented tailing backfill. The results of the training and testing dataset are given in Figures 4(a) and 4(b), respectively.
Good agreements can be observed between the actual and predicted strength, indicated by the higher $R$ values ( 0.9887 for the training dataset and 0.9811 for the actual dataset). Lower values of RMSE ( 0.1358 for the training dataset and 0.1482 for the testing dataset) can also be found for the comparison. These comparing results showed that the proposed combining model ( $\mathrm{RF}$ and FA) has a high accuracy to predict the compressive strength of the cemented tailing backfill.

Figure 5 gives the comparison results of the training and testing dataset with the horizontal line to characterize the difference between the actual and predicted compressive strength of the cemented tailing backfill.

Good agreements can be also observed between the comparison results, except for the few noise points, but these results are acceptable for the proposed model (combing the $\mathrm{RF}$ and FA) to predict the compressive strength of the cemented tailing backfill.

5.2. Importance of the Variable. The compressive strength of the cemented tailing backfill was accurately predicted by the proposed method combing the RF and FA. By using the RF, the relative importance of the varying design parameters to the compressive strength can also be determined. Figure 6 presents the results. 


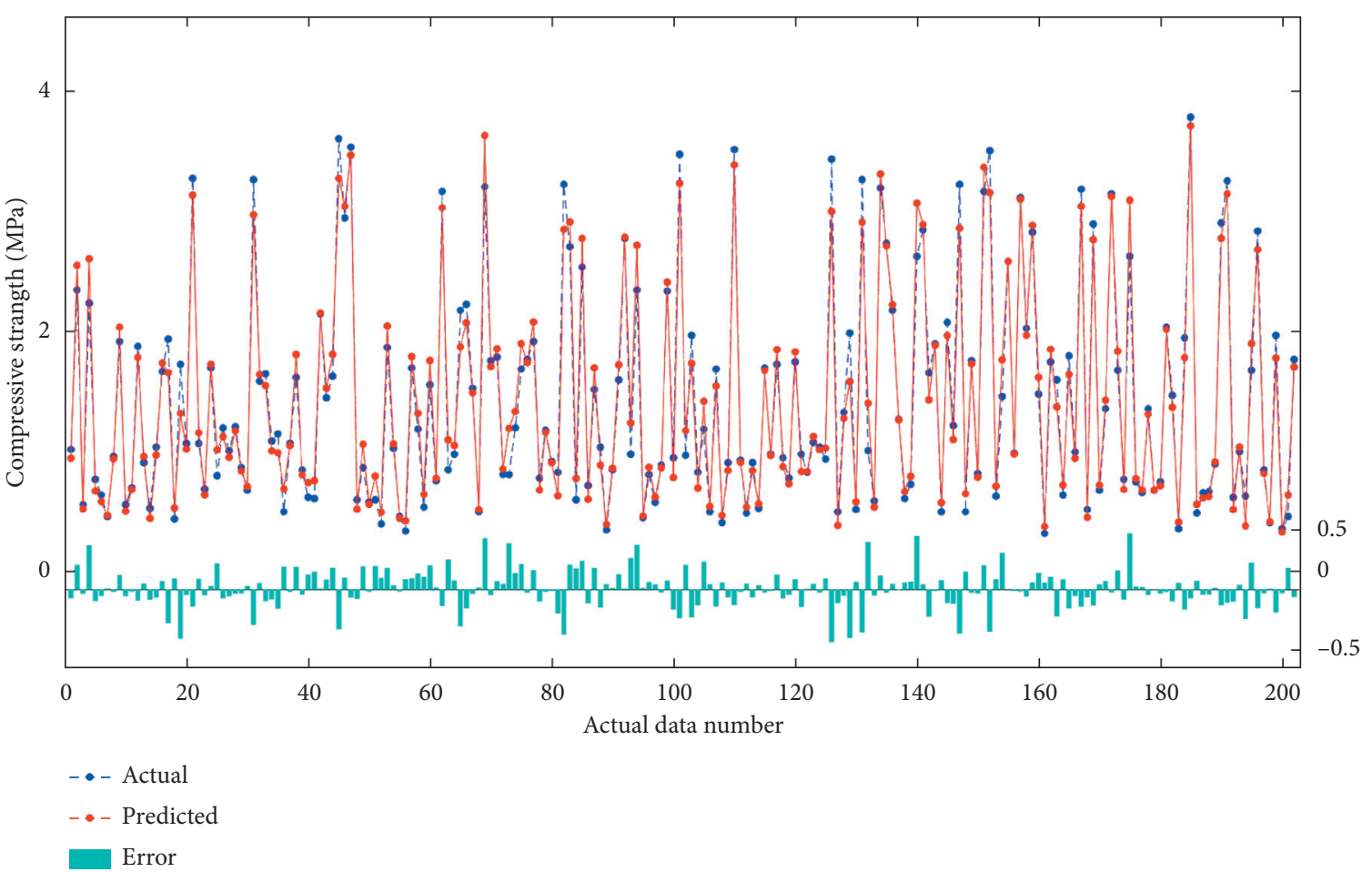

Figure 5: Comparisons of the predicted and actual compressive strength of the cemented tailing backfill.

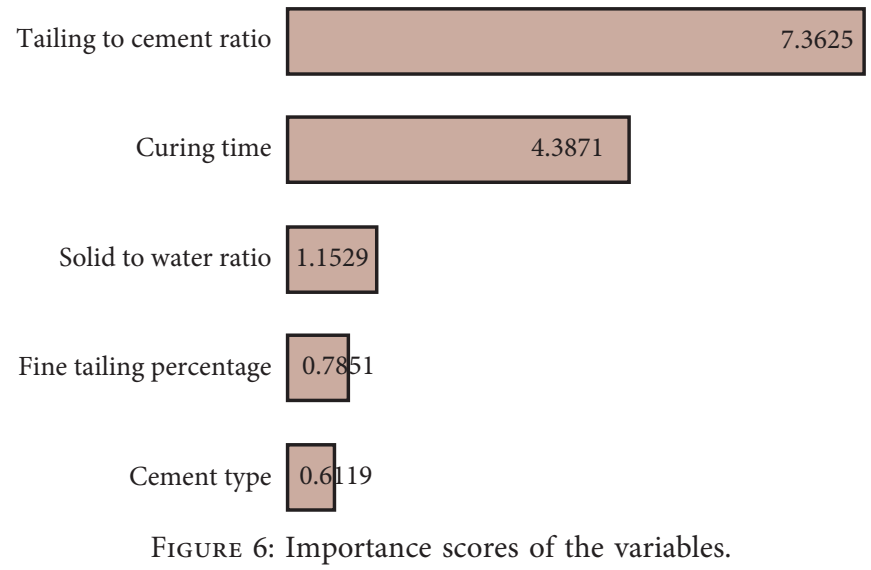

It is evident that the tailing to cement ratio is the most important parameter to the compressive strength of the cemented tailing backfill, with an importance score of 7.3625 , followed by the curing time. The influence of the three design parameters (solid to water ratio, fine tailing percentage, and cement type) is relatively weak compared with the tailing to cement ratio and curing time. Therefore, the design of the cemented tailing backfill should have the focus on the tailing to cement ratio and curing time, instead of the solid to water ratio, fine tailing percentage, and cement type. Such a conclusion can be used in the future design guideline for the cemented tailing backfill.

\section{Conclusions}

In the present study, the research process to use artificial intelligence algorithms to predict the compressive strength of cemented tailing backfill was conducted, overcoming the shortcomings of traditional empirical formulas. Experimental tests to measure the compressive strength of cemented tailing backfill were conducted to construct the dataset for the machine learning. Five input parameters (tailing to cement ratio, percentage of fine tailings, cement type, curing time, and solid to water ratio) were considered for the design of the laboratory tests. The FA was used to 
tune the RF hyperparameters, and it was adopted to combine the RF model to improve the accuracy and efficiency for the prediction of the compressive strength of the cemented tailing backfill. The results of the training and testing dataset were compared regarding the measured and actual compressive strength, respectively. By comparing the predicted and actual results, a good correlation was confirmed, indicating the reliability and accuracy of the prediction model proposed in this study. Regarding the importance of the different design parameters, it was confirmed that tailing to cement ratio and curing time are the two most important parameters to the compressive strength of the cemented tailing backfill.

For the future development, more laboratory tests will be performed and the continuously updated database will be collected to improve the accuracy of the model to predict the compressive strength of cemented tailing backfill. Besides, the performance of other artificial intelligence models will be compared in the prediction to enhance this study.

\section{Data Availability}

The data used to support the findings of this study are available from the corresponding author upon request.

\section{Conflicts of Interest}

The authors declare that they have no conflicts of interest.

\section{Authors' Contributions}

Qi-Ang Wang and Jiandong Huang conceptualized the study and developed the methodology; Qi-Ang Wang and Jia Zhang were involved in original draft preparation. All authors have read and agreed to the published version of the manuscript.

\section{Acknowledgments}

This research was funded by the Fundmental Research Funds for the Central Universities under Award Number 2019QNA20.

\section{References}

[1] R. Wu, P. Kulatilake, H. Luo et al., "Design of the key bearing layer and secondary mining technology for previously mined areas of small coal mines," Rock Mechanics and Rock Engineering, vol. 54, pp. 1-15, 2019.

[2] N. Sivakugan, R. Rankine, K. Rankine et al., "Geotechnical considerations in mine backfilling in Australia," Journal of Cleaner Production, vol. 14, no. 12-13, pp. 1168-1175, 2006.

[3] M. Sheshpari, "A review of underground mine backfilling methods with emphasis on cemented paste backfill," Electronic Journal of Geotechnical Engineering, vol. 20, no. 13, pp. 5183-5208, 2015.

[4] M. Fall, M. Benzaazoua, and E. G. Saa, "Mix proportioning of underground cemented tailings backfill," Tunnelling and Underground Space Technology, vol. 23, no. 1, pp. 80-90, 2008.

[5] L. Lang, K.-I. Song, D. Lao, and T.-H. Kwon, "Rheological properties of cemented tailing backfill and the construction of a prediction model," Materials, vol. 8, no. 5, pp. 2076-2092, 2015.

[6] S. Yin, A. Wu, K. Hu, Y. Wang, and Y. Zhang, "The effect of solid components on the rheological and mechanical properties of cemented paste backfill," Minerals Engineering, vol. 35, pp. 61-66, 2012.

[7] Y. Sun, G. Li, J. Zhang et al., "Development of an ensemble intelligent model for assessing the strength of cemented paste backfill," Advances in Civil Engineering, vol. 2020, Article ID 1643529, , 2020.

[8] Y. Sun, G. Li, H. Basarir, A. Karrech, and M. R. Azadi, "Laboratory evaluation of shear strength properties for cement-based grouted coal mass," Arabian Journal of Geosciences, vol. 12, no. 22, p. 690, 2019.

[9] I. González-Taboada, B. González-Fonteboa, F. MartínezAbella, and J. L. Pérez-Ordóñez, "Prediction of the mechanical properties of structural recycled concrete using multivariable regression and genetic programming," Construction and Building Materials, vol. 106, pp. 480-499, 2016.

[10] T. Grice, "Underground mining with backfill," in Proceedings of the 2nd Annual Summit-Mine Tailings Disposal Systems, Brisbane, Australia, November 1998.

[11] B. D. Thompson, W. F. Bawden, and M. W. Grabinsky, "In situ measurements of cemented paste backfill at the Cayeli Mine," Canadian Geotechnical Journal, vol. 49, no. 7, pp. 755-772, 2012.

[12] K. G. Kolovos, P. G. Asteris, and S. Tsivilis, "Properties of sandcrete mixtures modified with metakaolin," European Journal of Environmental and Civil Engineering, vol. 20, no. sup1, pp. s18-s37, 2016.

[13] M. Kamal, R. Rumman, T. Manzur, M. A. Noor, and M. S. Bari, "A novel durability based concrete mix design using supplementary cementitious materials and modified aggregate band gradation," International Journal of Civil Engineering, vol. 19, pp. 1-12, 2021.

[14] M. A. Getahun, S. M. Shitote, and Z. C. Abiero Gariy, "Artificial neural network based modelling approach for strength prediction of concrete incorporating agricultural and construction wastes," Construction and Building Materials, vol. 190, pp. 517-525, 2018.

[15] A. K. Das, D. K. Mishra, J. Yu et al., "Smart self-healing and self-sensing cementitious composites-recent developments, challenges, and prospects," Advances in Civil Engineering Materials, vol. 8, no. 3, pp. 554-578, 2019.

[16] Y. Sun, J. Zhang, G. Li, Y. Wang, J. Sun, and C. Jiang, "Optimized neural network using beetle antennae search for predicting the unconfined compressive strength of jet grouting coalcretes," International Journal for Numerical and Analytical Methods in Geomechanics, vol. 43, no. 4, pp. 801813, 2019

[17] Y. Sun, J. Zhang, G. Li et al., "Determination of Young's modulus of jet grouted coalcretes using an intelligent model," Engineering Geology, vol. 252, pp. 43-53, 2019.

[18] Y. Sun, G. Li, N. Zhang et al., "Development of ensemble learning models to evaluate the strength of coal-grout materials," International Journal of Mining Science and Technology, vol. 31, 2020.

[19] J. Huang, Y. Zhang, Y. Sun, J. Ren, Z. Zhao, and J. Zhang, "Evaluation of pore size distribution and permeability reduction behavior in pervious concrete," Construction and Building Materials, vol. 290, Article ID 123228, 2021.

[20] J. Huang, J. Zhang, J. Ren, and H. Chen, “Anti-rutting performance of the damping asphalt mixtures (DAMs) made 
with a high content of asphalt rubber (AR)," Construction and Building Materials, vol. 271, Article ID 121878, 2021.

[21] J. Huang and Q.-A. Wang, "Influence of crumb rubber particle sizes on rutting, low temperature cracking, fracture, and bond strength properties of asphalt binder," Materials and Structures, vol. 54, no. 2, p. 54, 2021.

[22] J. Huang, Y. Sun, and J. Zhang, "Reduction of computational error by optimizing SVR kernel coefficients to simulate concrete compressive strength through the use of a human learning optimization algorithm," Engineering with Computers, vol. 37, 2021.

[23] J. Huang, G. Shiva Kumar, J. Ren, Y. Sun, Y. Li, and C. Wang, "Towards the potential usage of eggshell powder as biomodifier for asphalt binder and mixture: workability and mechanical properties," International Journal of Pavement Engineering, vol. 22, pp. 1-13, 2021.

[24] J. Huang, M. Losa, P. Leandri, S. G. Kumar, J. Zhang, and Y. Sun, "Potential anti-vibration pavements with damping layer: finite element (FE) modeling, validation, and parametrical studies," Construction and Building Materials, vol. 281, Article ID 122550, 2021.

[25] J. Huang, P. Leandri, G. Cuciniello, and M. Losa, "Mix design and laboratory characterisation of rubberised mixture used as damping layer in pavements," International Journal of Pavement Engineering, vol. 22, pp. 1-15, 2021.

[26] J. Huang, G. S. Kumar, and Y. Sun, "Evaluation of workability and mechanical properties of asphalt binder and mixture modified with waste toner," Construction and Building Materials, vol. 276, Article ID 122230, 2021.

[27] J. Huang, T. Duan, Y. Zhang et al., "Predicting the permeability of pervious concrete based on the beetle antennae search algorithm and random forest model," Advances in Civil Engineering, vol. 2020, Article ID 8863181, 11 pages, 2020.

[28] J. Huang, G. Cuciniello, P. Leandri et al., "Design of rubberized asphalt mixtures for noise and vibration damping layers," in Proceedings of the Advances in Materials and Pavement Performance Prediction II: Contributions to the 2nd International Conference on Advances in Materials and Pavement Performance Prediction (AM3P 2020), CRC Press, San Antonio, TX, USA, May 2020.

[29] J. Huang, R. Alyousef, M. Suhatril et al., "Influence of porosity and cement grade on concrete mechanical properties," Advances in Concrete Construction, vol. 10, no. 5, pp. 393-402, 2020.

[30] L. Breiman, "Random forests," Machine Learning, vol. 45, no. 1, pp. 5-32, 2001.

[31] Y. Sun, G. Li, J. Zhang et al., "Prediction of the strength of rubberized concrete by an evolved random forest model," Advances in Civil Engineering, vol. 2019, Article ID 5198583, 7 pages, 2019.

[32] R. E. Schapire, "The boosting approach to machine learning: an overview," in Nonlinear Estimation and Classification, pp. 149-171, Springer, New York, NY, USA, 2003.

[33] R. J. Hyndman and A. B. Koehler, "Another look at measures of forecast accuracy," International Journal of Forecasting, vol. 22, no. 4, pp. 679-688, 2006.

[34] R. Boddy and G. Smith, Statistical Methods in Practice: For Scientists and Technologists, John Wiley \& Sons, New York, NY, USA, 2009.

[35] U. Braga-Neto and E. Dougherty, "Bolstered error estimation," Pattern Recognition, vol. 37, no. 6, pp. 1267-1281, 2004.

[36] R. J. Tibshirani and B. Efron, "An introduction to the bootstrap," Monographs on Statistics and Applied Probability, vol. 57, pp. 1-436, 1993.
[37] J.-H. Kim, "Estimating classification error rate: repeated cross-validation, repeated hold-out and bootstrap," Сomputational Statistics \& Data Analysis, vol. 53, no. 11, pp. 3735-3745, 2009.

[38] M. Stone, "Cross-validatory choice and assessment of statistical predictions," Journal of the Royal Statistical Society: Series B, vol. 36, no. 2, pp. 111-133, 1974.

[39] R. Kohavi, A Study of Cross-Validation and Bootstrap for Accuracy Estimation and Model Selection, IJCAI, Montreal, Canada, 1995. 